\author{
Bartosz BRZOZOWSKI ${ }^{1}$ \\ Przemysław KORDOWSKI ${ }^{2}$ \\ Zdzisław ROCHALA ${ }^{3}$ \\ Konrad WOJTOWICZ ${ }^{4}$
}

\title{
METODY SKANOWANIA PRZESTRZENI W SYSTEMIE ANTYKOLIZYJNYM BSP
}

\begin{abstract}
Wiedza o rozmieszczeniu obiektów na trasie przelotu bezzałogowego statku powietrznego (BSP) jest zagadnieniem bardzo istotnym z punktu widzenia nawigacji i sterowania statku powietrznego. Pozwala przede wszystkim na wyznaczenie trajektorii lotu omijającej obszary niebezpieczne dla statku powietrznego. W Zakładzie Awioniki i Uzbrojenia Lotniczego są prowadzone badania mające na celu opracowanie systemu antykolizyjnego dla bezpilotowych statków powietrznych (BSP) pionowego startu i lądowania. Wykorzystując czujnik URG-04LX firmy Hokuyo, zaproponowano dwie, różniące się sposobem skanowania, struktury trójwymiarowego laserowego skanera przestrzeni. Zasada działania skanera wynika przede wszystkim z przyjętej trajektorii ruchu czujnika i pozwala na uzyskanie odmiennych chmur punktów obrazujących obiekty wokół BSP. W przypadku gdy ruch czujnika jest ortogonalny do płaszczyzny skanowania, skanowanie jest realizowane metodą liniową. Natomiast metoda skanowania polegająca na obrocie płaszczyzny skanowania wokół osi skierowanej zgodnie z wektorem ruchu statku powietrznego została nazwana metodą obrotową. Wymienione metody posiadają określone, unikatowe cechy, które zostały opisane na podstawie porównania uzyskanych wyników doświadczalnych.
\end{abstract}

Słowa kluczowe: bazzałogowy statek powietrzny, metody skanowania, system antykolizyjny

\section{Wprowadzenie}

Wykrywanie przeszkód na trasie przelotu BSP jest zagadnieniem bardzo istotnym z punktu widzenia nawigacji i sterowania. Wiedza o rozmieszczeniu obiektów pozwala przede wszystkim na wyznaczenie trajektorii lotu omijającej

\footnotetext{
${ }^{1}$ Autor do korespondencji/corresponding author: Bartosz Brzozowski, Wojskowa Akademia Techniczna, ul. S. Kaliskiego 2, 00-908 Warszawa, tel. (22) 6839851, e-mail: bbrzozowski @wat.edu.pl

${ }^{2}$ Przemysław Kordowski, przemekkordowski@gmail.com

${ }^{3}$ Zdzisław Rochala, zrochala@wat.edu.pl

${ }^{4}$ Konrad Wojtowicz, kwojtowicz@wat.edu.pl
} 
obszary niebezpieczne dla statku powietrznego. Ponadto może ona w znacznym stopniu wspomagać proces określania pozycji. W przypadku lotów na otwartej przestrzeni do określania położenia stosuje się przede wszystkim układy zliczeniowe wspierane przez system nawigacji satelitarnej GPS. Z kolei wewnątrz pomieszczeń, gdy GPS nie jest w stanie określić pozycji, informacje pochodzące z systemu antykolizyjnego mogą wspomagać korygowanie bieżących współrzędnych BSP. W literaturze można znaleźć przykłady różnych rozwiązań systemów nawigacji i wykrywania przeszkód wewnątrz pomieszczeń [1-3]. Wyznaczanie pozycji oraz wykrywanie przeszkód jest realizowane przez specjalnie w tym celu opracowane algorytmy działające na podstawie informacji pochodzących z czujników ultradźwiękowych lub wizyjnych. W prezentowanym projekcie zrealizowanym przez zespół z Zakładu Awioniki i Uzbrojenia Lotniczego Wojskowej Akademii Technicznej zastosowano czujnik laserowy Hokuyo URG-04LX o długości fali z zakresu podczerwonego. Umożliwia on skanowanie przestrzeni w jednej płaszczyźnie w zakresie 240 stopni, a jego zasięg wynosi $5 \mathrm{~m}$. Poprzez wprowadzenie czujnika w ruch możliwe jest uzyskanie trójwymiarowej chmury punktów.

\section{Porównanie metod skanowania przestrzeni}

Urządzenie pomiarowe zostało zaprojektowane tak, aby możliwe było, wykorzystując te same elementy mechaniczne, a zmieniając jedynie położenie czujnika i oprogramowanie mikrokontrolera, zastosowanie obydwu opracowanych metod skanowania przestrzeni. Pierwsza metoda określona jako liniowa polega na ruchu czujnika w kierunku ortogonalnym do płaszczyzny skanowania (rys. 1a). W tym przypadku obszar skanowany przez urządzenie określa przestrzeń w postaci ostrosłupa czworokątnego o kącie wierzchołkowym równym 120 stopni [4]. W drugiej metodzie płaszczyzna skanowania jest obracana wokół osi skierowanej równolegle do osi podłużnej samolotu (rys. 1b). Metoda ta została określona jako obrotowa, gdyż w skutek obrotu płaszczyzny skanowania punkty pomiarowe układają się w postaci koncentrycznych okręgów, a skanowany obszar określa przestrzeń w kształcie stożka o kącie rozwarcia równym 120 stopni [5]. Za pomocą podstawowych wzorów matematycznych można obliczyć, że przestrzeń obejmowana przez czujnik w metodzie liniowej jest o około 21,5\% większa niż w metodzie obrotowej.

Wprowadzenie w ruch czujnika laserowego URG-04LX w obydwu opracowanych metodach odbywa się za pomocą serwomechanizmu modelarskiego o dużym momencie obrotowym. Na orczyku serwomechanizmu jest zawieszona obudowa skanera wykonana ze stopu aluminium. Z kolei element wykonawczy jest zamontowany do podstawy zaprojektowanego urządzenia wykonanej również ze stopu aluminium. Za sterowanie czujnikiem i serwomechanizmem odpowiada mikrokontroler AT90USB firmy Atmel. Został on wybrany przede wszystkim ze względu na udostępnienie przez producenta bibliotek do obsługi 
a)

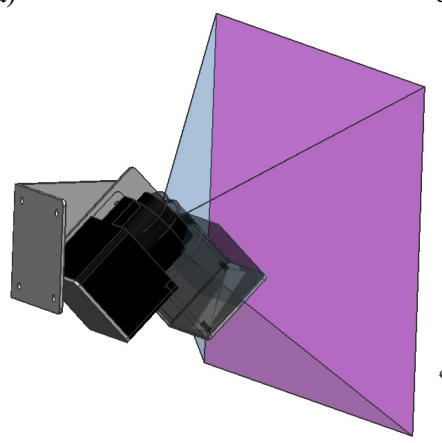

b)

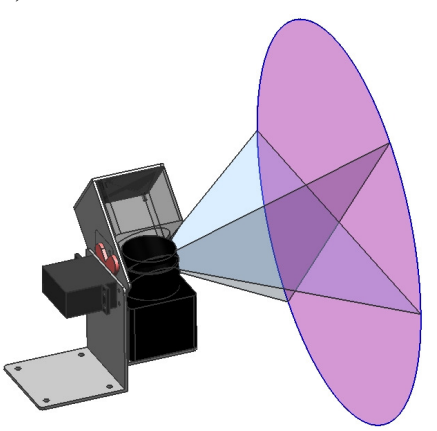

Rys. 1. Porównanie zasady działania liniowej (a) i obrotowej (b) metody skanowania

Fig. 1. Comparison of operation principle of linear (a) and rotational (b) scanning methods

urządzeń USB CDC, niezbędnych do połączenia z czujnikiem laserowym. Mikrokontroler za pomocą jednego z interfejsów RS232, SPI lub I2C komunikuje się z komputerem pokładowym BSP. Z komputera pokładowego jest wysyłana informacja o inicjalizacji pomiaru zawierająca jako parametr wartość skoku serwomechanizmu z zakresu od 1 do 9 stopni. Po zakończeniu skanowania do stacji bazowej są przesyłane dane zawierające trzy parametry dla każdego punktu pomiarowego: odległość, kąt odchylenia promienia lasera oraz kąt ustawienia serwomechanizmu. W zależności od wybranej metody został zastosowany odpowiedni algorytm transformacji danych do prostokątnego układu współrzędnych, które następnie zostają zapisane oraz przesłane do stacji naziemnej. Opracowane algorytmy wykrywają obszary niebezpieczne w tak otrzymanej chmurze punktów [6].

Zmiany wartości skoku serwomechanizmu powodują różne rozdzielczości pomiarów. W przypadku metody liniowej zwiększanie skoku powoduje pomijanie odpowiedniej rosnącej liczby linii (rys. 2.). Skutkuje to problemami z wykrywaniem niewielkich obiektów usytuowanych poziomo, o wysokości nieprzekraczającej kilkunastu centymetrów. Z kolei w metodzie obrotowej nawet dla największego skoku obszar bezpośrednio przed skanerem jest obrazowany z większą rozdzielczością niż dla najmniejszego skoku w metodzie liniowej (rys. 3.). Ponadto dla każdej skanowanej linii jest wykonywany pomiar odległości do obiektów znajdujących się na przedłużeniu osi obrotu czujnika zgodnej z osią podłużną statku powietrznego.

Zastosowany czujnik powoduje największe ograniczenia funkcjonalne zaprojektowanego systemu. Przede wszystkim czas skanowania w jednej płaszczyźnie niezależnie od ustawionego zakresu pomiarowego wynosi $100 \mathrm{~ms}$. $\mathrm{Z}$ tego powodu całkowity czas niezbędny do otrzymania chmury punktów z największą dokładnością wynosi kilkanaście sekund. System ten może więc 


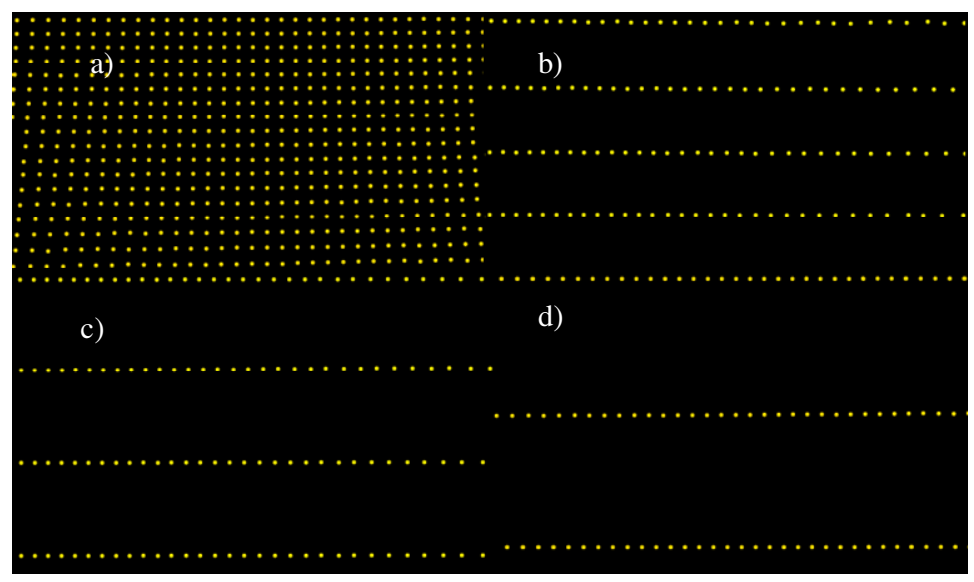

Rys. 2. Zobrazowanie wykrywania płaskiej tablicy w metodzie liniowej dla wartości skoku serwomechanizmu: a) $1^{\circ}$, b) $5^{\circ}$, c) $7^{\circ}$, d) $9^{\circ}$

Fig. 2. The presentation of detection of flat board by using linear method for the following values of servomechanism stroke: a) $1^{\circ}$, b) $5^{\circ}$, c) $7^{\circ}$, d) $9^{\circ}$

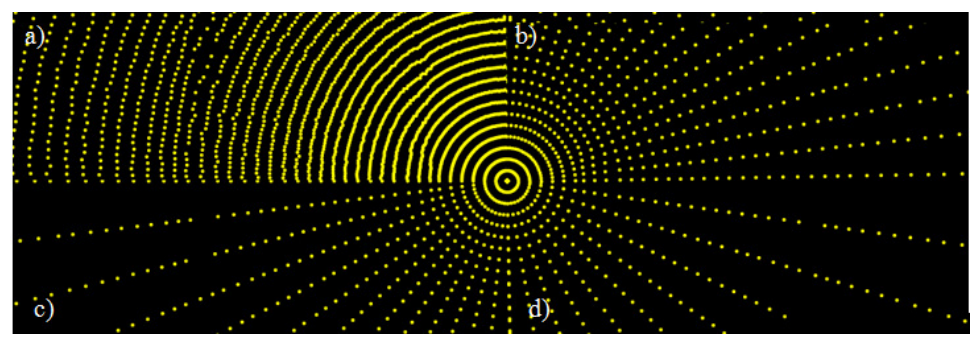

Rys. 3. Zobrazowanie wykrywania płaskiej tablicy w metodzie obrotowej dla wartości skoku serwomechanizmu: a) $1^{\circ}$, b) $5^{\circ}$, c) $7^{\circ}$, d) $9^{\circ}$

Fig. 3. The presentation of detection of flat board by using rotational method for the following values of servomechanism stroke: a) $1^{\circ}$, b) $5^{\circ}$, c) $7^{\circ}$, d) $9^{\circ}$

być stosowany wyłącznie w obiektach, które mają możliwość utrzymywania stałej pozycji w zawisie, a wykonywanie pomiarów w trakcie ruchu postępowego powoduje błędne wskazania. W celu skrócenia czasu pomiaru zastosowano zmienną wartość skoku serwomechanizmu. W metodzie liniowej ustawienie go na więcej niż 5 stopni uniemożliwia poprawną interpretację wyników zarówno przez opracowane algorytmy wykrywania przeszkód, jak i operatora obserwującego wizualizację na ekranie stacji naziemnej. W takim przypadku wąskie przedmioty są bardzo często omijane przez układ pomiarowy, narażając BSP na kolizję. Problem ten został rozwiązany poprzez opracowanie metody obrotowej, która wyróżnia się kilkoma zaletami w stosunku do metody liniowej. Przede wszystkim niezależnie od ustawionego skoku serwomechanizmu punkty pomia- 
rowe tworzą współśrodkowe okręgi, a nie są rozmieszczone w równych odstępach, co w znacznym stopniu ogranicza możliwość pominięcia przeszkody. Umożliwia to znaczne skrócenie czasu skanowania, gdyż nawet przy największym skoku algorytmy są w stanie określić obszary niebezpieczne dla lotu. Ponadto w każdym położeniu serwomechanizmu środkowy pomiar jest wykonywany wzdłuż osi podłużnej statku powietrznego, co pozwala na opracowanie algorytmu, który umożliwi w trakcie wykonywania przelotu weryfikację obecności obiektów na trajektorii lotu.

Przeprowadzono wiele badań weryfikujących zdolności wykrywania przeszkód przez opracowany system antykolizyjny. W większości przypadków obie metody równie wiarygodnie określały obszary niebezpieczne dla BSP. Jak już wspomniano, najbardziej problematyczne ze względu na możliwości detekcyjne czujnika są wąskie poziome i pionowe obiekty. Podczas lotów wewnątrz budynków tego typu elementy najczęściej występują jako pręty, rury i belki. $\mathrm{Z}$ tego powodu jeden z cykli badań obejmował wykrywanie krat wykonanych z prętów o średnicy $15 \mathrm{~mm}$ i kątowników o grubości $35 \mathrm{~mm}$ (rys. 4a). W metodzie liniowej zadowalające efekty uzyskano jedynie w przypadku pomiarów wykonanych w odległości mniejszej niż 1,0 m pomiędzy czujnikiem i obiektem ze skokiem 1 stopnia. Wówczas wykrywane były zarówno kątowniki, jak i niektóre pręty. Powyżej $1,5 \mathrm{~m}$ i dla większych wartości skoku serwomechanizmu pojawiały się
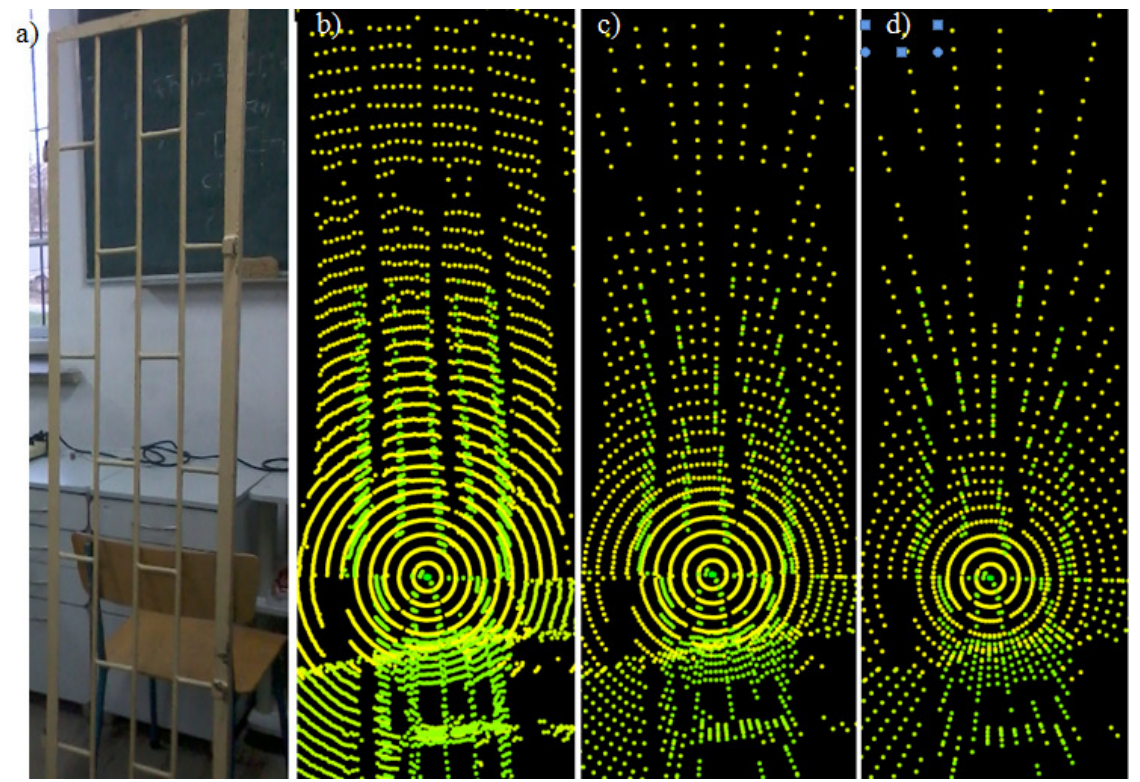

Rys. 4. Wykrywanie kraty (a) umieszczonej w odległości 1,0 m od czujnika w metodzie obrotowej dla wartości skoków serwomechanizmu: b) $1^{\circ}$, c) $5^{\circ}$, d) $7^{\circ}$

Fig. 4. Detection of grate (a) placed in the distance of $1.0 \mathrm{~m}$ from sensor by using rotational method for servomechanism stroke: b) $1^{\circ}$, c) $5^{\circ}$, d) $7^{\circ}$ 
wyłącznie pojedyncze punkty, które nie mogły zostać poprawnie zinterpretowane przez algorytm. Zdecydowanie lepsze wyniki otrzymano dla metody obrotowej (rys. 4.) - w odległości 1,0 m krata była wykrywana w przypadku zmiany skoku aż do 7 stopni. Powyżej tej wartości możliwe było wykrycie jej elementów wyłącznie przez kilka środkowych punktów pomiarowych, gdyż nawet przy największym skoku rozdzielczość dla tych punktów jest większa niż przy najmniejszym skoku w metodzie liniowej. Ponadto fragmenty kraty były wykrywane już z odległości $2,0 \mathrm{~m}$.

Wizualizacja danych może być przeprowadzona w dwojaki sposób. Przede wszystkim służy do tego odpowiedni moduł w opracowanej aplikacji do obsługi systemu. Punkty pomiarowe zostają zobrazowane na płaszczyźnie, gdzie odległość jest określona poprzez zmianę koloru od zielonego, przez żółty, do czerwonego. Ponadto po wyeksportowaniu danych pomiarowych możliwa jest ich wizualizacja $\mathrm{w}$ dowolnym programie przeznaczonym do pracy $\mathrm{z}$ chmurami punktów. Bardziej czytelne wyniki dla ludzkiego oka są otrzymywane metodą liniową. Należy zauważyć, że w metodzie obrotowej dużo większy wpływ na poprawne odzwierciedlenie skanowanego obszaru ma dokładność wykonania i montażu elementów mechanicznych. W przypadku gdy podstawa stanowiska i obudowa czujnika nie są umieszczone w płaszczyznach wzajemnie ortogonalnych, pojawiają się błędy w postaci braku spójności danych (rys. 4b-d).

\section{Podsumowanie}

W wyniku prowadzonych badań w Zakładzie Awioniki i Uzbrojenia Lotniczego Wojskowej Akademii Technicznej opracowano dwa systemy skanowania przestrzeni na potrzeby budowy systemu antykolizyjnego dla BSP. Zdecydowanie lepszymi parametrami charakteryzuje się system wykorzystujący metodę obrotową. Niestety największe ograniczenia funkcjonalne zaprojektowanych urządzeń narzuca zastosowany czujnik, dlatego też praktyczne zastosowanie oraz dalszy rozwój systemu jest uzależniony od zastąpienia obecnie używanego układu pomiarowego innym o lepszych parametrach technicznych przy zbliżonych lub mniejszych parametrach, takich jak: zapotrzebowanie na energię, masa i wymiary.

\section{Literatura}

[1] Sobers D.M., Chowdhary G., Johnson E.N.: Indoor navigation for unmanned aerial vehicles. Proc. AIAA Guidance, Navigation and Control Conference, Chicago 2009.

[2] Mohamed K.M., Patra S., Lanzon A.: Designing simple indoor navigation system for UAVs. Proc. of 19th Miditerranean Conference on Control and Automation, Greece 2011.

[3] Watanabe Y., Calise A.J., Johnson E.N.: Vision-based obstacle avoidance for UAVs. Proc. of AIAA Guidance, Navigation and Control Conference and Exhibit, Hilton Head 2007. 
[4] Brzozowski B., Kordowski P., Rochala Z., Wojtowicz K.: Project of a miniature 3D LIDAR for VTOL UAVs. Pomiary, Automatyka, Robotyka PAR, 2 (2013), 68-71.

[5] Brzozowski B., Kordowski P., Rochala Z., Wojtowicz K.: System antykolizyjny Z wizualizacją otoczenia dla BSP. VII Konferencja Awioniki, Krasiczyn 2013.

[6] Brzozowski B., Kordowski P., Mazurek P., Rochala Z., Wojtowicz K.: Modelowanie przestrzeni wokół BSP na potrzeby bezpiecznego wykonywania autonomicznego lotu. 52. Sympozjum „Modelowanie w Mechanice”, Ustroń 2013.

\title{
SURROUNDINGS SCANNING METHODS IN UAV'S ANTI-COLLISION SYSTEM
}

\begin{abstract}
A bstract
The knoweledge of the objects arrangement on the air way of unmanned aerial vehicles is a very significant problem in terms of navigation and control of aircraft. Primarily, it allows to determine the flight trajectory passing by the airspace dangerous for aircraft. In the Department of Avionics and Air Armament researches to develop an anti-collision system for vertical take-off and landing (VTOL) unmanned aerial vehicles (UAV) are conducted. Basing on Hokuyo URG04LX two structures of three dimensional laser airspace scanners that differ in scanning method sensor, were proposed. Scanner's principle of operation results mostly from chosen movement trajectory of the sensor and allows to obtain different point clouds visualizing objects around UAV. When the sensor movement is orthogonal to the scanning plane, such scanning is performed using linear method. On the other hand, the method in which scanning is performed by rotating scanning plane around axis parallel to heading vector of the UAV was called rotational. Mentioned methods have determined, unique features, which were described basing on comparison of obtained experimental results.
\end{abstract}

Keywords: unmanned aerial vehicle, scanning methods, anti-collision system

DOI:10.7862/rm.2013.35

Otrzymano/received: $15.09 .2013 \mathrm{r}$.

Zaakceptowano/accepted: 22.11.2013 r. 